\title{
A STUDY OF TRAUMATIC INTRACEREBRAL HAEMATOMAS IN A TEACHING HOSPITAL OF CENTRAL INDIA
}

\author{
Nayak Ashok1, Singh Lal Mani², Sajith Babu S. Mํ
}

${ }^{1}$ Assistant Professor, Department of Neurosurgery, S. S. Medical College, Rewa, Madhya Pradesh. ${ }^{2}$ Assistant Professor, Department of General Surgery, S. S. Medical College, Rewa, Madhya Pradesh. ${ }^{3}$ RSO, Department of General Surgery, S. S. Medical College, Rewa, Madhya Pradesh.

\begin{abstract}
\section{BACKGROUND}

A study of 50 cases of Traumatic Intracerebral Haematomas was carried out to study the factors affecting management and prognosis. Incidence of Intracerebral Haematomas was more than other Intracranial Haematomas. Young male adults were affected most. Vehicular accident was the commonest mode of injury. Computed tomography was the definitive investigation. Hypertension, bradycardia and associated convulsions carried bad prognosis. Glasgow Coma Scoring was a good indicator of outcome. Commonest site was the Temporal Lobe, Multiple Haematomas and Haematomas involving Brainstem and Basal-Ganglia carried poor prognosis. Mortality was $61.53 \%$ and $33.3 \%$ in operated and non-operated groups respectively. Most small Haematomas ( $<15 \mathrm{~mm}$ on CT scan) were treated conservatively, whereas the large ones ( $>25 \mathrm{~mm})$ surgically.
\end{abstract}

\section{KEYWORDS}

Computed Tomography, Traumatic, Intracerebral Haematomas.

HOW TO CITE THIS ARTICLE: Ashok N, Mani SL, Babu SSM. A study of traumatic intracerebral haematomas in a teaching hospital of central India. J. Evolution Med. Dent. Sci. 2016;5(40):2439-2441, DOI: 10.14260/jemds/2016/568

\section{INTRODUCTION}

Increasing incidence of Head injuries today constitutes it a major public health problem. With the advent of Computed Tomography, Traumatic Intracerebral Haematomas are being detected more frequently. Therefore, early diagnosis and accurate radiological assessment and surgery of these lesions have improved the overall outcome. In this study an attempt is made to assess the various factors, which may govern the line of management of these patients.

\section{MATERIAL AND METHODS}

50 cases of Traumatic Intracerebral Haematomas admitted in Department of Surgery, S.S. Medical College, Rewa, during July 2013 to March 2015 were analysed. Clinical examination which included Glasgow Coma Scoring and detailed neurological assessment was carried out. X-ray skull and Computed Tomography of brain was performed in all these cases to confirm the site and extent of the Haematomas.

\section{RESULTS}

Of all Intracranial Haematomas, incidence of Intracerebral Haematomas was maximum, i.e. $36.5 \%$ as compared to Extradural (31\%) and Subdural (32.5\%) Haematomas. Considering all Head injury admissions, incidence of Intracerebral Haematomas was $2.7 \%$; 32 cases (64\%) had only Intracerebral Haematomas and rest 18 cases (36\%) were associated with Extradural and/or subdural haematomas. Of fifty cases, 24 were treated conservatively with 33.3\% mortality. Rest was treated surgically with $61.53 \%$ mortality.

Financial or Other, Competing Interest: None.

Submission 17-01-2016, Peer Review 30-04-2016,

Acceptance 04-05-2016, Published 18-05-2016.

Corresponding Author:

Dr. Singh Lal Mani,

Assistant Professor

Department of General Surgery,

SGM Hospital, Rewa-486001,

Madhya Pradesh.

E-mail: lalmnsingh@gmail.com

DOI: $10.14260 /$ jemds $/ 2016 / 568$
Amongst the operated group, mortality was more in cases which were associated with other intracranial haematomas. Showing the Age and Sex incidence in different age groups, it shows peak incidence in third decade. It also reveals $84 \%$ Males as compared to $16 \%$ Females only.

\begin{tabular}{|c|c|c|c|c|}
\hline \multirow{2}{*}{$\begin{array}{l}\text { Sl. } \\
\text { No. }\end{array}$} & \multirow{2}{*}{ Age } & \multirow{2}{*}{ No. } & \multicolumn{2}{|c|}{ Sex } \\
\hline & & & Male & Female \\
\hline 1 & $0-10$ & 03 & 01 & 02 \\
\hline 2 & $11-20$ & 06 & 05 & 01 \\
\hline 3 & $21-30$ & 19 & 16 & 03 \\
\hline 4 & $31-40$ & 08 & 08 & 00 \\
\hline 5 & $41-50$ & 10 & 09 & 01 \\
\hline 6 & 51 \& Above & 04 & 03 & 01 \\
\hline \multirow{2}{*}{\multicolumn{3}{|c|}{$\begin{array}{c}50 \\
\text { Table } 1 \\
\end{array}$}} & 42 & 08 \\
\hline & & & & \\
\hline
\end{tabular}

Showing Glasgow Coma Score at the time of admission. It shows Mortality was $100 \%$ in patients having score in between 3-5 and it gradually reduced with increasing score. Mortality being only 26\% in 13-15 score group.

\begin{tabular}{|c|c|c|c|c|}
\hline G.C.S. & $\begin{array}{c}\text { Total } \\
\text { No. }\end{array}$ & $\begin{array}{c}\text { Operated/ } \\
\text { Outcome }\end{array}$ & $\begin{array}{c}\text { Non- } \\
\text { operated/ } \\
\text { Outcome }\end{array}$ & $\begin{array}{c}\text { Deaths } \\
\text { (Total) }\end{array}$ \\
\hline $03-05$ & 10 & $7 / 7$ & $3 / 3$ & $\begin{array}{c}10 \\
(100 \%)\end{array}$ \\
\hline $06-09$ & 15 & $10 / 7$ & $5 / 3$ & $\begin{array}{c}10 \\
(75 \%)\end{array}$ \\
\hline $10-12$ & 10 & $3 / 2$ & $7 / 2$ & $\begin{array}{c}04 \\
(40 \%)\end{array}$ \\
\hline $13-15$ & 15 & $6 / 2$ & $9 / 2$ & $\begin{array}{c}04 \\
(26 \%)\end{array}$ \\
\hline Total & 50 & $26 / 18$ & $24 / 10$ & 28 \\
\hline \multicolumn{4}{|c|}{ Table 2} \\
\hline
\end{tabular}

Showing relationship of mortality with the site of Haematoma. In the present series, highest incidence of Haematomas was found in Temporal lobe. Haematomas found in Occipital, Cerebellar or involving Brain-stem Basal nuclei had almost $80-100 \%$ mortality. 


\begin{tabular}{|c|c|c|c|c|}
\hline $\begin{array}{c}\text { Sl. } \\
\text { No. }\end{array}$ & $\begin{array}{c}\text { Site of } \\
\text { Haematoma }\end{array}$ & $\begin{array}{c}\text { Total } \\
\text { No. }\end{array}$ & Deaths & Percentage \\
\hline 1 & Frontal & 09 & 02 & 22.22 \\
\hline 2 & Temporal & 13 & 06 & 46.15 \\
\hline 3 & Parietal & 11 & 03 & 27.27 \\
\hline 4 & Occipital & 01 & 01 & 100.00 \\
\hline 5 & Cerebellar & 01 & 01 & 100.00 \\
\hline 6 & $\begin{array}{c}\text { Brain Stem \& } \\
\text { Basal Nuclei }\end{array}$ & 05 & 04 & 80.00 \\
\hline 7 & Multiple & 10 & 09 & 90.00 \\
\hline \multicolumn{5}{|c|}{ Table 3 } \\
\hline
\end{tabular}

Showing outcome in relation to size of Haematomas and mass effect on CT scan.

Maximum cases were of small size ( $<15 \mathrm{~mm}$ on CT scan) and mortality was $35 \%$ in this group. Large sized Haematomas were found in nine cases. Out of them seven were operated with $60 \%$ mortality and two were treated conservatively with $100 \%$ mortality.

\begin{tabular}{|c|c|c|c|}
\hline $\begin{array}{c}\text { Size of } \\
\text { Haematoma }\end{array}$ & $\begin{array}{c}\text { Total } \\
\text { No. }\end{array}$ & $\begin{array}{c}\text { Mass- } \\
\text { Effect }\end{array}$ & $\begin{array}{c}\text { Outcome/ } \\
\text { operated }\end{array}$ \\
\hline $\begin{array}{c}\text { Small } \\
(0-15 \mathrm{~mm})\end{array}$ & 18 & 03 & $\begin{array}{c}13 \text { improved } / 3 \\
5 \text { died } / 1\end{array}$ \\
\hline $\begin{array}{c}\text { Medium } \\
(16-25 \mathrm{~mm})\end{array}$ & 15 & 05 & $\begin{array}{c}8 \text { Improved } / 2 \\
7 \text { died } / 5\end{array}$ \\
\hline $\begin{array}{c}\text { Large } \\
(>25 \mathrm{~mm})\end{array}$ & 09 & 08 & $\begin{array}{c}3 \text { Improved/3 } \\
6 \text { died } / 4\end{array}$ \\
\hline \multicolumn{4}{|c|}{ Table 4 } \\
\hline
\end{tabular}

\section{DISCUSSION}

Incidence of Traumatic Intracerebral Haematomas is being reported more often after the advent of Computerized Tomography. In our study, the incidence is $2.7 \%$ as compared to $0.4 \%$ (B. Ramamurthy 1980).[1]

Study of pre-CT era, Gopal Baratham (1972).[2] revealed maximum intracerebral haematomas in late age group (60-80 years) like subdural haematomas, but in our study with CT scan facility it is evident that the peak incidence was found between 21 and 30 yrs., similar to Jamieson's study.[3] Highest mortality was noticed above 40 yrs. as observed by other studies.[3]

In our study most of the cases were of early onset (Within 72 hours), but in other studies T Ninchoji et al (1984).[4] have found significant (4 out of 250) cases developed delayed increase in size of haematoma (Bolinger Apoplexy), in which prognosis is grave.

Maximum cases were due to road side vehicular accidents, which are more in comparison to other studies, J. Yelland's - 38\%, (1972).[5] Two wheelers were responsible for most of the vehicular accidents. Demierre B. (1987).[6] revealed the pathophysiology of development of delayed traumatic intracerebral haematoma, but in our study we have not come across any patients of delayed traumatic intracerebral haematoma.

Present study revealed $34 \%$ cases with hypertension and $8 \%$ with bradycardia on admission as compared to $3 \%$ to $14 \%$ in J. Yelland's study (1972).[5] Incidence of hemiplegia was only $22 \%$ as compared to $50 \%$ in J and Yelland's study and $56 \%$ in McLaurin and McBride study (1956).[5],[7]

Koziiarski A. (1991).[8] had observed that not only the size of haematoma is the criteria for surgical intervention, they have also noted poor results of patient having multiple haematomas, deep seated like thalamic/basal ganglion.
Few patients have mortality due to other systematic complications. In our study also we have observed poor outcome in the patients of multiple haematomas and deep seated haematomas (Thalamic/Basal ganglion).

In our study, maximum number of haematomas were observed in temporal lobe (46.15\%) followed by parietal lobe (27.27\%). Other studies showed predominantly temporal lobe involvement Jamieson 50\%, McLaurin 75\%; Browder $55 \%,[3],[7],[9]$ As seen in study of Kase-Williams, operative results of large size haematomas were better in present study also.[10]

Multiple haematomas had poor outcome, particularly with the involvement of Brain stem and Basal nuclei. T. Mathisen.[11] study shows that surgical evacuation was indicated in ICH of more than $20 \mathrm{~mL}$ with mass effect and radiological signs. Patients with ICH more than $50 \mathrm{~mL}$ were operated early and give good results. These patients had exclusively ICH only, no associated other extracerebral haematomas along with our observation is similar to above study.

Patients with medium sized haematomas were considered candidates for surgical evacuation when there was marked mass effect on computed tomography or a decline in the level of consciousness.

Ravindra Kumar Garg (2015).[12] emphasises the importance of timely intervention for surgery and coupled with good neuro-critical care for better result. We also feel that timely decision for surgical intervention and good neurointensive care remain an important factor for better outcome.

R. Bullock and Chang.[13],[14] had observed that ICP monitoring was tried in this study, but they observed that it was unable to predict the late onset sudden rise in pressure instead of ICP monitoring obliteration of basal cisterns pears to be more reliable indicator for severity of injury we agree with the observation of above study

Virat Harsh et al and D. D'evella et al[15],[16] noted that the poor prognosis was observed in the patients having GCS-7 or below. In our study also, similar results were observed.

\section{REFERENCES}

1. Ramamurthy B. PN tondon text book of neurosurgery 1980;1:252-9.

2. Gopal Baratham, William G Dennyson. Delayed traumatic intracerebral haemorrhage. Journal of Neurology, Neurosurgery and Psychiatry 1972;35(5):698-706.

3. Jamieson KC, Yelland JD. Traumatic intracerebral haematoma report of 63 surgically treated cases. J Neurosurg 1972;37(5):528-32.

4. Ninchoji T, Uemura K, Shimoyama I. Traumatic intracerebral haematomas of delayed onset. Acta Neurochirurgica 1984;71(1):69-90.

5. John DN Yelland. Surgically treated traumatic subdural haematomas. Journal of Neurosurgery 1972;37(2):137-49.

6. Demierre B, Schoenle PW, Hori A, et al. Post-traumatic intracerebral haematoma. Neuro chirurgie 1987;33(1):126.

7. McLaurin RL, McBride. Traumatic intracerebral haematoma review of 16 surgically treated cases. Annals of Surgery 1956;143(3):294-305.

8. Koziarski A. Conservative treatment of post-traumatic intracerebral haematoma. Neurol Neurochir Pol 1991;25(2):230-7. 
9. Browder EJ, Corradini EW. Surgical treatment of intracerebral haematoma. AMA Arch Neurol Psychiatry 1951;65:112-7.

10. Kase CS, Williams. Lobar intracerebral haematoma. Clinical and CT analysis of 22 cases Neurology 1982;32(10):114650 .

11. Mathiesen T, Kakarieka A, Edner G. Traumatic intracerebral lesions without extracerebral haematoma in 218 patients. Acta Neurochi 1995;137(34):155-63.

12. Ravindra K, Sridhar K, Mazda K Turel, et al. A summary of some of the recently published seminal papers in neuroscience. Neurology India 2015;63(6):947-57.
13. Bullock R, Golek J, Blake G. Traumatic intracerebral haematoma-which patients should undergo surgical evacuation? CT scan features and ICP monitoring as a basis for decision making. Surg Neurol 1989;32(3):181-7.

14. Chang EF, Meeker M, Holland MC. Acute traumatic intraparenchymal haemorrhage: risk factors for progression in the early post-injury period. Neurosurgery 2006;58(4):647-56.

15. Viraat Harsh, Anand Prakasha, James Marcellus Barry, et al. Traumatic intracerebellar haematoma: to operate or not to operate? British Journal of Neurosurgery 2015;29(3):53-7.

16. D'Avella D, Cacciola F, Angileri FF, et al. Traumatic intracerebellar haemorhagic contusions and haematomas. J Neurosurg Sci 2001;45(1):29-37. 